\title{
塔里木盆地中深1C井原油高聚硫代金刚烷及 金刚烷硫醇的检出及意义
}

\author{
马安来 ${ }^{1,2^{*}}$, 金之钧 $^{1}$, 朱翠山 ${ }^{3}$, 顾忆 ${ }^{1}$ \\ 1. 中国石油化工股份有限公司石油勘探开发研究院, 北京 100083; \\ 2. 有机地球化学国家重点实验室, 广州 510640; \\ 3. 长江大学资源与环境学院, 武汉 434000 \\ *E-mail: maal.syky@sinopec.com
}

收稿日期：2017-12-25; 收修改稿日期：2018-04-19; 接受日期：2018-06-11; 网络版发表日期：2018-08-23 国家自然科学基金项目(批准号：41772153)、有机地球化学国家重点实验室开放基金课题(编号：SKLOG-201702)、国家科技重大专项项目 (编号: 2017ZX05005-002)和中国石油化工股份有限公司科技部项目(编号: P16090、P17049-1)资助

\begin{abstract}
摘要中深1井、中深1C井为塔里木盆地寒武系盐下油气突破的钻井, 中下寒武统油气藏地球化学特征及次生蚀 变作用存在差异. 对中深1C井下寒武统肖尔布拉克组原油进行浓缩, 浓缩原油的含硫非烃组分中检测到高聚硫代 金刚烷和金刚烷硫醇系列, 包括硫代四金刚烷、四金刚烷硫醇、硫代五金刚烷、五金刚烷硫醇, 浓缩原油的饱和 烃组分中检测到高聚金刚烷系列，包括四金刚烷、五金刚烷、六金刚烷、环六金刚烷.分析了上述化合物质谱， 并与国外文献比对，确定了上述化合物的存在. 高聚硫代金刚烷可能是在TSR作用下高聚金刚烷受到硫自由基攻 击, 发生开笼作用, 先形成似高聚金刚烷硫醇, 然后进一步环化形成高聚硫代金刚烷. 使用 $\mathrm{D}_{16}$-单金刚烷作为定量 内标, 中深 $1 \mathrm{C}$ 井下寒武统原油低聚金刚烷和低聚硫代金刚烷含量分别为 83874 和 $8578 \mu \mathrm{g} / \mathrm{g}$, 远高于中深 1 井中寒武 统原油及相关奥陶系原油中的低聚金刚烷和低聚硫代金刚烷含量. 高含量的低聚金刚烷、高含量的低聚硫代金 刚烷及高聚硫代金刚烷和高聚金刚烷硫醇系列的检出进一步证实中深1C井原油为强烈TSR作用的残余油.
\end{abstract}

关键词塔里木盆地, 寒武系, 中深 $1 \mathrm{C}$ 井, 高聚硫代金刚烷, 高聚金刚烷硫醇, 高聚金刚烷, 硫酸盐热化学还原反应

\section{1 引言}

金刚烷化合物为分子式为 $\mathrm{C}_{4 n+6} \mathrm{H}_{4 n+12}$ 的笼形烃类, 其基本重复单元是一个含有 10 个碳的单金刚烷，这些 基本重复单元很大程度上叠置在金刚石的晶格中，形 成空间互锁的结构(Wingert, 1992; Dahl等, 2003a; Ali Massort等, 2012; 马安来, 2016). 低聚金刚烷是指分子
结构中单金刚烷重复单元小于等于 3 的金刚烷,包括单 金刚烷、双金刚烷和三金刚烷，高聚金刚烷是指分子 结构中单金刚烷重复单元大于 3 的金刚烷分子，包括 四金刚烷、五金刚烷、六金刚烷等. 规则迫位缩合的 高聚金刚烷同分异构体遵循 $\mathrm{C}_{4 n+6} \mathrm{H}_{4 n+12}$ 的分子式，不规 则迫位缩合和沙位缩合的高聚金刚烷同分异构体分子 式不同于规则迫位缩合同分异构体的分子式(Lin和 
Wilk，1999; Dahl等，2003a，2003b; Ali Massort等, 2012). 由于金刚烷独特的分子结构, 性质稳定, 广泛用 于成熟度(Chen等, 1996; Wei等, 2006a, 2006b; Sassen 和Post, 2008)、生物降解(Grice等, 2000; Wei等, 2006b, 2007a)、原油裂解(Dahl等, 1999)、TSR评价中(王广利 等, 2013; Cai等, 2016a, 2016b). 硫代金刚烷为金刚烷 笼形结构中一个或多个碳原子被硫原子所取代，金刚 烷硫醇为硫醇类化合物，其金刚烷笼形结构中仲碳或 季碳或侧链中键合了-SH官能团(Wei等，2011)。自Hanin等(2002)提出2-硫代单金刚烷作为油气藏遭受TSR 作用的分子标志物以来，研究多侧重应用低聚硫代金 刚烷含量及低聚硫代金刚烷单体化合物 $\delta^{34} \mathrm{~S}$ 判别油气 藏遭受TSR的强度、划分原油类型(Wei等，2007b, 2012; Gvirtzman等, 2015; Cai等, 2016a, 2016b; Zhu 等, 2015a, 2016).

相对于低聚金刚烷和低聚硫代金刚烷，高聚金刚 烷、高聚硫代金刚烷、高聚金刚烷硫醇含量低，需要 富集原油样品才能满足检测下限要求(Lin 和Wilk, 1995; Dahl等, 2003a, 2003b, 2010; Wei等, 2011), 目前 从原油中分离的高聚金刚烷最高可至十一金刚烷 (Dahl等，2003b)，高聚金刚烷的含量和内组成可用作 划分高-过成熟原油不同油簇的指标(Moldowan等, 2013, 2015; Dahl等, 2017). 而原油中已鉴定出的高聚 硫代金刚烷及高聚金刚烷硫醇的最高笼数只达到六笼 (Wei等，2011)，高聚硫代金刚烷和高聚金刚烷硫醇可 以作为TSR作用的分子标志物并可用来预测酸性气体 的产能(Wei等, 2011). 在强烈TSR蚀变的原油中, 还可 检测到烷基多硫代金刚烷(Wei等, 2011; Cai等, 2016a).

中深1井、中深1C井为塔里木盆地寒武系盐下油 气突破井, 对中深 1 井、中深 $1 \mathrm{C}$ 井寒武系原油和天然 气的地球化学特征, 前人进行了大量的研究(王招明 等, 2014; Li等, 2015; Zhang等, 2015a, 2015b; Zhu等, 2015a, 2015b, 2016; 宋到福等, 2016; 王道伟等, 2016; Cai等, 2016a, 2016b; 张纪智等, 2017). 中寒武统、下 寒武统油气藏在油气藏性质、地球化学特征上的差 异, 部分研究者认为中寒武统、下寒武统油气藏分别 来自中上奥陶统烃源岩和寒武系烃源岩( $\mathrm{Li}$ 等，2015; 宋到福等, 2016; 王道伟等, 2016); 另一部分研究者认 为中寒武及下寒武统油气藏均来自寒武系烃源岩(王 招明等, 2014; Cai等, 2015, 2016a, 2016b; 张纪智等, 2017), 两套油气藏在地球化学特征的差异则归因于下
寒武统肖尔布拉克组油气藏经历了硫酸盐热化学还原 作用(TSR)(Cai等, 2016a，2016b)及中、下寒武统油气 藏差异聚集的结果(张纪智等, 2017). 文献使用含硫化 合物如苯并噻吩、二苯并噻吩、硫代单金刚烷和硫代 双金刚烷单体硫同位素证实了中深1C井原油遭受了 TSR作用(Zhang等, 2015a; Li等, 2015; Cai等, 2016b), 然而对于中深1C井肖尔布拉克组原油遭受TSR作用强 度的认识存在差异. Li等(2015)、Cai等(2016b)、Zhu 等(2016)认为中深1C井肖尔布拉克组原油经历了强烈 的TSR作用，Zhu等(2015b)认为中深1C井液态烃经历 了TSR作用，而天然气未受到TSR作用，Zhang等 (2015b) 提出中深1C井可视为TSR蚀变作用的典型原 油, 但文中未强调TSR的强度.

本文对中深 $1 \mathrm{C}$ 井下寒武统肖尔布拉克组原油经 挥发浓缩富集重质烃类，在浓缩原油饱和烃组分鉴定 出高聚金刚烷，首次鉴定出环六金刚烷; 在浓缩原油 含硫非烃中首次鉴定高聚硫代金刚烷和金刚烷硫醇系 列, 定量分析了中深1C井、中深1井寒武系原油及相 关奥陶系原油中低聚硫代金刚烷、低聚金刚烷含量, 旨在分析讨论高聚硫代金刚烷及高聚金刚烷硫醇地质 意义及在油气藏蚀变中的应用, 进一步证实了中深1C 井原油为强烈TSR作用的残余油.

\section{2 样品与实验}

\section{1 样品}

样品采自中深1C井下寒武统肖尔布拉克组原油, 样品埋深6861 6944m, 储层温度为 $165^{\circ} \mathrm{C}$, 储层压力为 74 75MPa(王招明等, 2014; 宋到福等, 2016). 为了对 比TSR作用对高聚硫代金刚烷及高聚金刚烷硫醇的影 响, 采集了中深1井中寒武统阿瓦塔格组原油及相关奥 陶系原油包括塔中83井、罗斯2井及顺北原油. 由于原 油中高聚硫代金刚烷及金刚烷硫醇含量较低，为了获 取高信噪比的质谱图, 称取 $1.0 \mathrm{~g}$ 中深1C井下寒武统原 油, 在 $50^{\circ} \mathrm{C}$ 的加热台上, 在 $\mathrm{N}_{2}$ 的保护下浓缩原油样品 至 $300 \mathrm{mg}$ ，用于柱色层分离饱和烃、芳烃和含硫非烃 组分.

\section{2 实验方法}

原油样品及浓缩后的原油样品通过传统的柱色层 方法获取饱和烃、芳烃组分, 分离后的饱和烃加入 
$\mathrm{C}_{24} \mathrm{D}_{50} 、 5 \alpha$-雄甾烷、 $\mathrm{D}_{16}$-单金刚烷用于正构烷烃、生 物标志物和金刚烷的定量内标，分离后的芳烃加入 $\mathrm{D}_{10}$ - 葱用于定量内标. 对原油和浓缩后的原油使用银 盐离子柱色层法分离含硫非烃(Wei等, 2007b; 姜乃煌 等, 2007), 用正已烷、二氯甲烷、丙酮洗脱分离柱, 获 得饱和烃、芳烃和含硫非烃(OSC). 分离后的有机硫 化物(OSC)加入适量 $\mathrm{D}_{16}$-单金刚烷, 用于硫代金刚烷定 量内标, 使用 $\mathrm{N}_{2}$ 缓吹将 $\mathrm{OSC}$ 组分浓缩至 $0.5 \mathrm{~mL}$, 用于色 质分析.

饱和烃和硫代金刚烷色质分析是在HP-Agilent 6890/5973 GC-MS仪器上完成的, 样品进行多离子和 全扫描分析，在全扫描分析中，扫描时间设置为 $1 \mathrm{~s}$, 扫 描质量范围50 500amu. 色谱柱为HP-5MS石英弹性色 谱柱 $(30 \mathrm{~m} \times 0.25 \mathrm{~mm} \times 0.25 \mu \mathrm{m})$. 饱和烃色质升温程序: $50^{\circ} \mathrm{C}$ 保持 $1 \mathrm{~min}$, 以 $20^{\circ} \mathrm{C} / \mathrm{min}$ 升温至 $100^{\circ} \mathrm{C}$, 然后以 $3^{\circ} \mathrm{C} / \mathrm{min}$ 升温至 $315^{\circ} \mathrm{C}$, 恒温 $16.83 \mathrm{~min}$. 硫代金刚烷色质 升温程序: $50^{\circ} \mathrm{C}$ 保持 $1 \mathrm{~min}$, 以 $3^{\circ} \mathrm{C} / \mathrm{min}$ 升温至 $310^{\circ} \mathrm{C}$, 恒 温 $14.33 \mathrm{~min}$. 传输线温度 $250^{\circ} \mathrm{C}$, 离子源温度为 $200^{\circ} \mathrm{C}$. $\mathrm{EI}$ 轰击模式, 电压 $70 \mathrm{eV}$, 样品在 $320^{\circ} \mathrm{C}$ 恒温下以不分流 模式分析, 载气为氦气, 流速 $1.0 \mathrm{~mL} / \mathrm{min}$.

\section{3 结果}

\section{1 中深1C井原油含硫非烃总离子流图}

图1显示了中深1C井寒武系肖尔布拉克组凝析油 (图1a)及浓缩后原油(图1b)含硫非烃色质总离子流图 (TIC). 从中深1C井寒武系凝析油含硫非烃总离子流图 中可以看出含硫非烃以低聚硫代金刚烷及金刚烷硫醇 为主(硫代单金刚烷及单金刚烷硫醇、硫代双金刚烷 及双金刚烷硫醇、硫代三金刚烷及三金刚烷硫醇). 硫 代四金刚烷及四金刚烷硫醇含量很低, 笼数大于 5 个的 硫代金刚烷无法检测. 浓缩后的原油非烃总离子流图 中, 可以检测出笼数大于 5 的硫代金刚烷和金刚烷硫醇.

\section{2 硫代四金刚烷和四金刚烷硫醇系列}

硫代四金刚烷和四金刚烷硫醇(附录1)(网络版附 录1, http://earthcn.scichina.com)的分子式为 $\mathrm{C}_{21+n} \mathrm{H}_{26+2 n} \mathrm{~S}$ $(n \geqq 0)$. 与低聚硫代金刚烷和金刚烷硫醇相同, 硫代四 金刚烷和四金刚烷硫醇具有较强的分子离子峰 $\left[\mathrm{M}^{+}\right]$ $=310+14 n$ (Wei等, 2011). $\mathrm{m} / z$ 310、324、338质量色谱 图展示了浓缩后的中深 $1 \mathrm{C}$ 井原油含硫非烃中硫代四

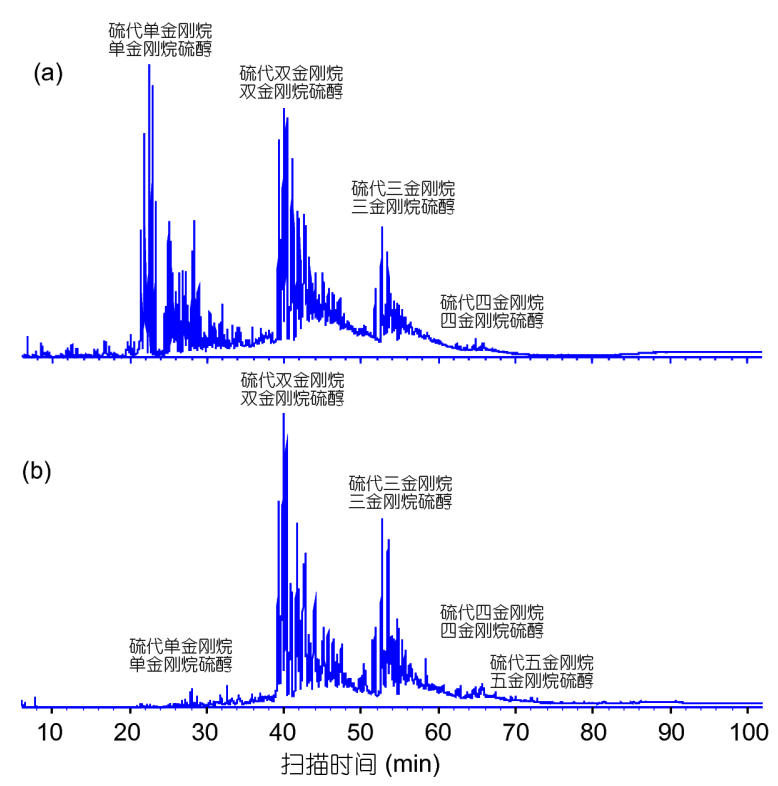

图 1 中深1C井凝析油(a)及浓缩后凝析油(b)含硫非烃总 离子流(TIC)图

金刚烷和四金刚烷硫醇系列的分布(图2).

\subsection{1 硫代四金刚烷系列}

$m / z \quad 310$ 质量色谱图中峰 $\mathrm{a} \sim \mathrm{c}$ 为无烷基取代的硫代 四金刚烷(图2a)，对于无烷基取代的硫代四金刚烷来 说，由于类似于四金刚烷的结构，因而无烷基取代的 硫代四金刚烷在质谱特征上通常表现为缺少碎片离

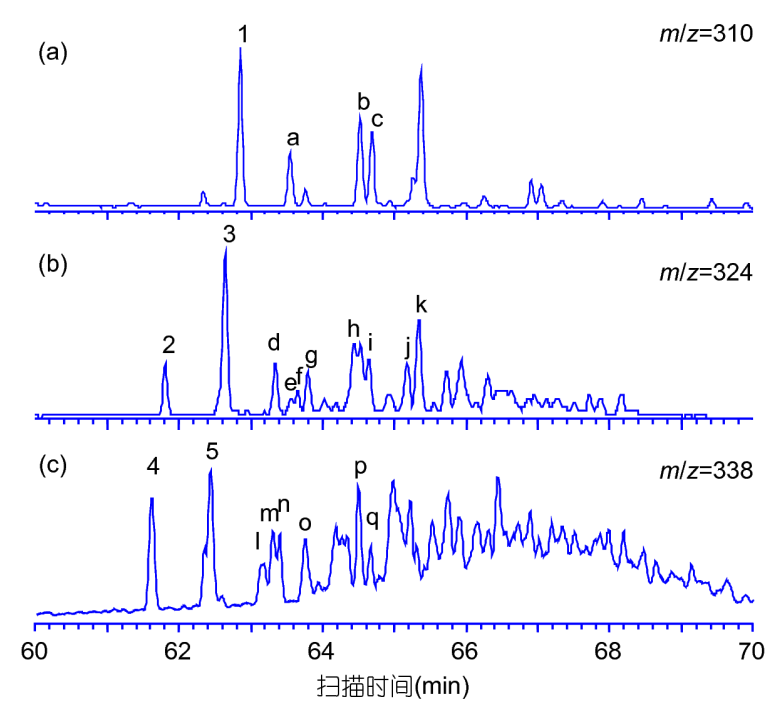

图 2 硫代四金刚烷和“假”四金刚烷硫醇(a)、 $\mathrm{C}_{1}$ 取代硫代 四金刚烷和四金刚烷硫醇 $(b) 、 C_{2}$ 取代硫代四金刚烷和 $C_{1}$ 取 代四金刚烷硫醇(c)质量色谱图 
子, 分子离子 $\left[\mathrm{M}^{+}\right]$即为基峰. 图3a显示了峰 $\mathrm{c}$ 的质谱图, 在质谱图中峰c具有较少的碎片离子, 基峰为 310 , 含有 134、277碎片离子, $m / z$ 277离子为[M-SH]特征离子, 同时含有较低丰度的 $m / z$ 324碎片离子, 该碎片离子为 $\mathrm{C}_{1}$ 烷基取代硫代四金刚烷的分子离子, 因而峰 $\mathrm{c}$ 可能是 硫代四金刚烷与 $\mathrm{C}_{1}$ 烷基取代的硫代四金刚烷共溢出. Wei等(2011)指出硫代四金刚烷(峰c)可能与 $\mathrm{C}_{1}$ 取代和 $\mathrm{C}_{2}$ 取代的硫代四金刚烷共溢出，在其质谱图中虽然以 $\mathrm{m} / \mathrm{z} 310$ 为基峰, 但是含有 $\mathrm{m} / \mathrm{z} 324 、 338$ 的碎片离子, $m / z 324 、 338$ 分别代表了 $\mathrm{C}_{1}$ 取代的硫代四金刚烷和 $\mathrm{C}_{2}$ 取代硫代四金刚烷的碎片离子，造成这种差异可能与 色质分析中色谱柱条件及升温速率有关.

根据质谱特征，中深 $1 \mathrm{C}$ 凝析油中存在 $\mathrm{C}_{1}$ 取代和 $\mathrm{C}_{2}$ 取代的硫代四金刚烷. $m / z$ 324质量色谱图中峰 $\mathrm{d} \sim$ 峰k 的化合物代表了 $\mathrm{C}_{1}$ 取代的硫代四金刚烷; $m / z$ 338质量 色谱图中峰1 q为二甲基硫代四金刚烷. 以峰i化合物
为例, 在质谱图中 $m / z$ 324为基峰(图3b), $m / z$ 310、291 强度较高, 同时含有较弱的 $m / z$ 338碎片离子, $m / z 324$ 为 $\mathrm{C}_{1}$ 取代硫代四金刚烷的分子离子, $m / z 310$ 代表了硫 代四金刚烷的分子离子, $\mathrm{m} / \mathrm{z} 338$ 碎片离子代表了 $\mathrm{C}_{2}$ 取 代硫代金刚烷的分子离子，因而图3b代表了 $\mathrm{C}_{1}$ 取代硫 代四金刚烷、硫代四金刚烷和 $\mathrm{C}_{2}$ 取代硫代四金刚烷的 共溢峰的质谱图. 此外峰i质谱图中 $m / z$ 277、291碎片 离子较强, 分别代表了 [310-SH]与[324-SH]特征离子, 这与Wei等(2011)提出峰 $\mathrm{i}$ 为 $\mathrm{C}_{1}$ 取代硫代四金刚烷与硫 代四金刚烷共溢出略有差异.

\subsection{2 “假”四金刚烷硫醇和四金刚烷硫醇系列}

依据Wei等(2011), 在中深1C井凝析油含有“假”四 金刚烷硫醇(附录1)(图2a峰1)和四金刚烷硫醇系列(附 录1, 图2b峰2、3)和甲基四金刚烷硫醇系列(图2c峰 4、5).
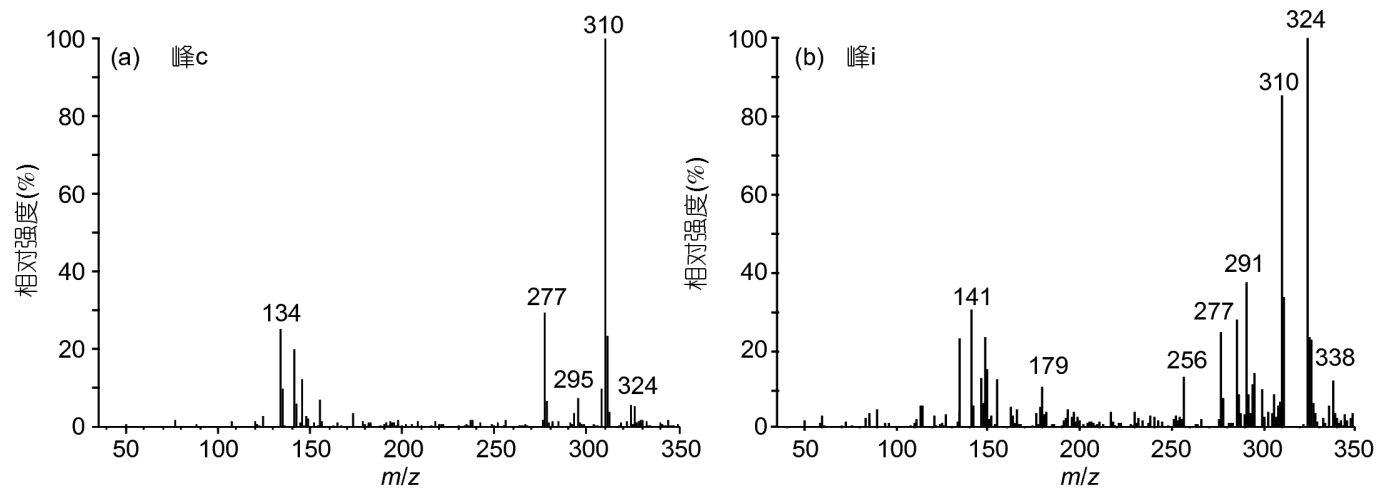

图 3 硫代四金刚烷系列质谱图

(a) 硫代四金刚烷(峰c)与 $\mathrm{C}_{1}$ 取代硫代四金刚(峰i)共溢出的质谱图; (b) $\mathrm{C}_{1}$ 取代硫代四金刚烷(峰i)、硫代四金刚烷(峰c)与 $\mathrm{C}_{2}$ 取代硫代四金刚烷 (峰q)共溢出的质谱图

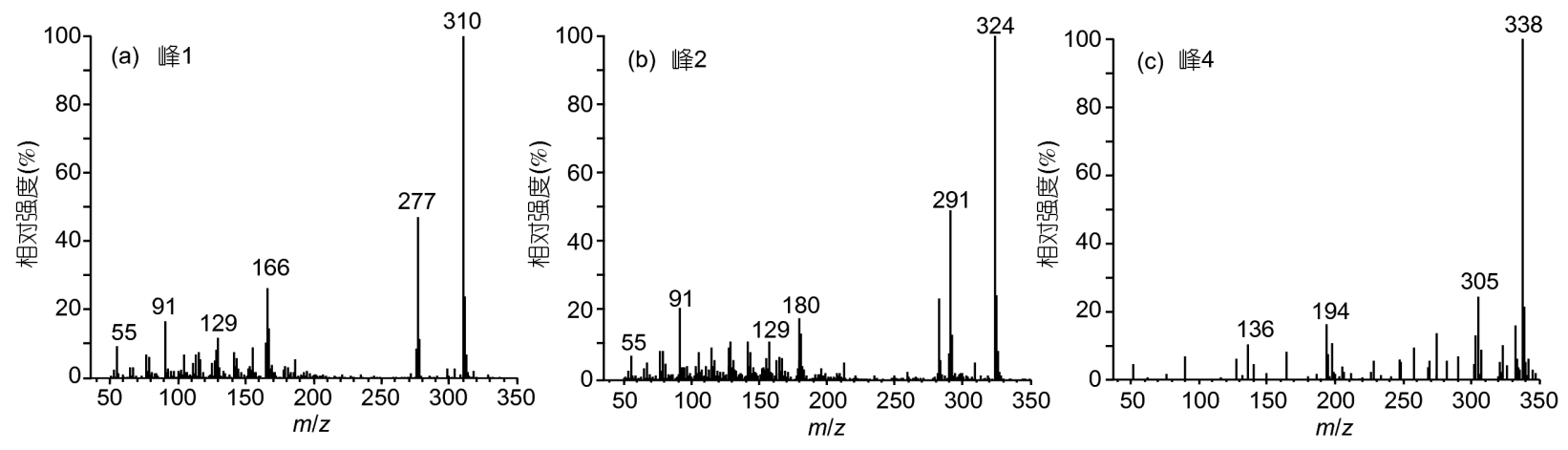

图 4 “假”四金刚烷硫醇(a)、四金刚烷硫醇(b)和甲基四金刚烷硫醇(c)质谱图 
由于四金刚烷硫醇的分子量为 $324, \mathrm{~m} / \mathrm{z} 310$ 质量 色谱图中峰 1 化合物并非四金刚烷硫醇, 而是结构类 似于四金刚烷硫醇的“假”四金刚烷硫醇化合物(Wei 等，2011). “假”四金刚烷硫醇、四金刚烷硫醇和甲基 四金刚烷硫醇含有 $[\mathrm{M}-\mathrm{SH}]$ 特征离子, 分别为 $m / z$ 277、 291、305. 此外, “假”四金刚烷硫醇、四金刚烷硫醇和 甲基四金刚烷硫醇含有 $\left[\mathrm{M}-\mathrm{C}_{8} \mathrm{H}_{16} \mathrm{~S}\right]$ 中性碎片离子，分 别为 $m / z$ 166、180、194(图4). “假”四金刚烷硫醇和四 金刚烷硫醇系列质量色谱图与Wei等(2011)发表的结 果基本一致.

\section{3 硫代五金刚烷和五金刚烷硫醇系列}

硫代五金刚烷和五金刚烷硫醇 (附录1)分子式为 $\mathrm{C}_{25+n} \mathrm{H}_{30+2 n} \mathrm{~S}(n \geqq 0)$, 分子离子 $\left[\mathrm{M}^{+}\right]=362+14 n . m / z$ 362、 376、390质量色谱图显示了浓缩后的中深1C井原油 含硫非烃中硫代五金刚烷和五金刚烷硫醇的分布 (图5).

\subsection{1 硫代五金刚烷系列}

$m / z$ 362质量色谱图显示了 4 个可能的硫代五金刚 烷(图 $5 \mathrm{a}$ 中峰A 峰D), $m / z$ 376质量色谱图显示了 5 个可 能的甲基硫代五金刚烷(图5b中峰E 峰I), 由于二甲基 硫代金刚烷含量低, 在 $m / z$ 390质量色谱图中未有明显 响应. 图6显示了硫代五金刚烷其中一个异构体的质谱 图, 与硫代四金刚烷相似, 硫代五金刚烷也以分子离子 为基峰, 同时含有 $[\mathrm{M}-\mathrm{SH}]$ 碎片离子 $m / z \quad 329$, 其他的碎 片离子如 $m / z$ 77、105、149、190, 这些离子的具体来 源有待进一步研究, Wei等(2011)认为在硫代五金刚烷 的其他碎片离子包括 $m / z$ 71、85、113、135、141、 239、291等似金刚烷笼形结构的碎片离子. $m / z$ 376质 量色谱图中峰E 峰I可能为五个甲基硫代五金刚烷, 由 于信噪比较低, 未能获得较好的质谱图.

\subsection{2 “假”五金刚烷硫醇和五金刚烷硫醇系列}

与“假”四金刚烷硫醇和四金刚烷硫醇分布相似， 中深1C井原油中含有“假”五金刚烷硫醇(附录 1 ; 图 $5 \mathrm{a}$, 6 号峰)、2个五金刚烷硫醇异构体(附录1)(图5b,7号峰 和 8 号峰)、2个甲基取代五金刚烷硫醇异构体(图 $5 \mathrm{c}, 9$ 号峰和 10 号峰).

由于五金刚烷硫醇的分子量是为 376 , 因而 $m / z$ 362 质量色谱图中的6号峰并非是五金刚烷硫醇, 而是

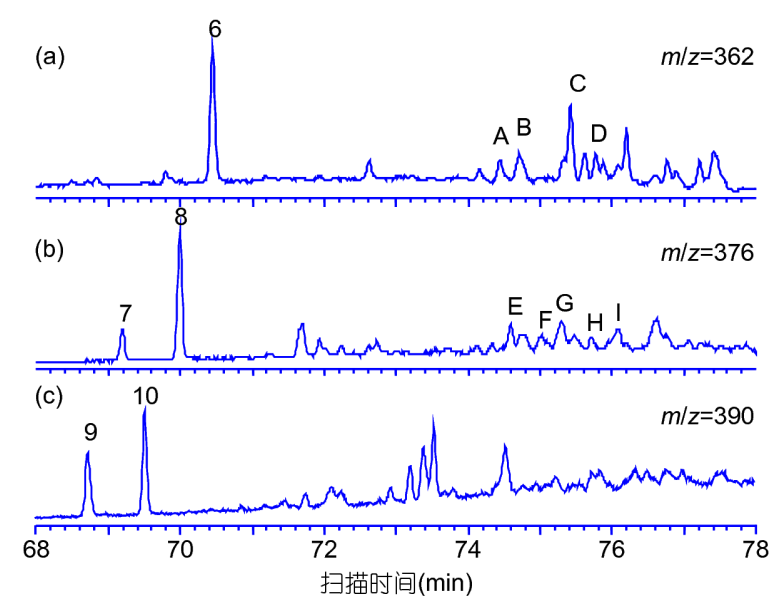

图 5 硫代五金刚烷和“假”五金刚烷硫醇(a)、甲基硫代五金 刚烷和五金刚烷硫醇(b)、甲基五金刚烷硫醇(c)质量色谱图

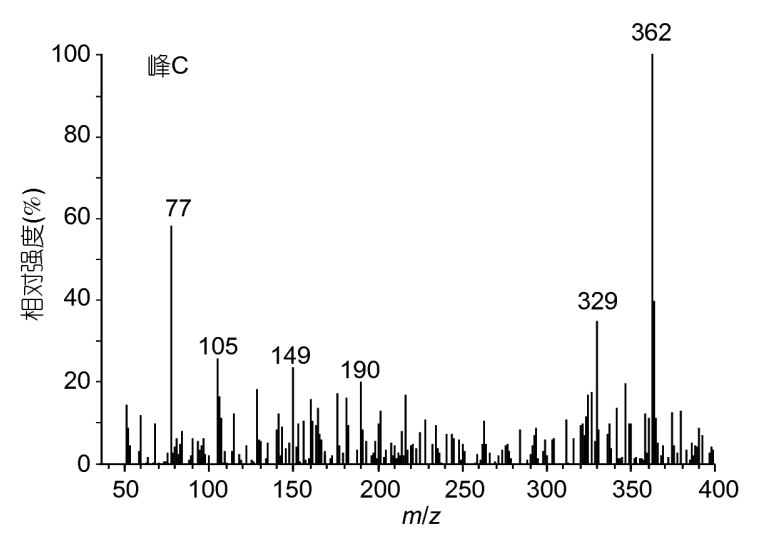

图 6 硫代五金刚烷(峰C)质谱图

“假”五金刚烷硫醇(Wei等, 2011). 在质谱图中 $m / z 362$ 为基峰(图7), 但 $m / z$ 329碎片离子强度明显高于硫代五 金刚烷的 $m / z$ 329碎片离子强度. 其他的碎片离子包括 $m / z$ 149、167和 181. 根据保留时间比对文献(Wei等, 2011), 7 号和 8 号峰可能为五金刚烷硫醇, 9 号和 10 号峰 可能为甲基五金刚烷硫醇. 由于 8 号峰中以 $m / z 57$ 为基 峰, 虽然含有较强的 $m / z$ 376、 $m / z$ 343离子, 笔者推测 8 号峰可能与其他化合物共溢出.

\section{4 四金刚烷系列}

中深1C井原油饱和烃中可检测出四金刚烷化合 物系列, 为了获取清晰的四金刚烷质谱图, 对中深 $1 \mathrm{C}$ 井浓缩原油进行了饱和烃色质分析. $m / z$ 292质量色谱 图显示了中深 $1 \mathrm{C}$ 井浓缩原油的 3 个可能的四金刚烷异 


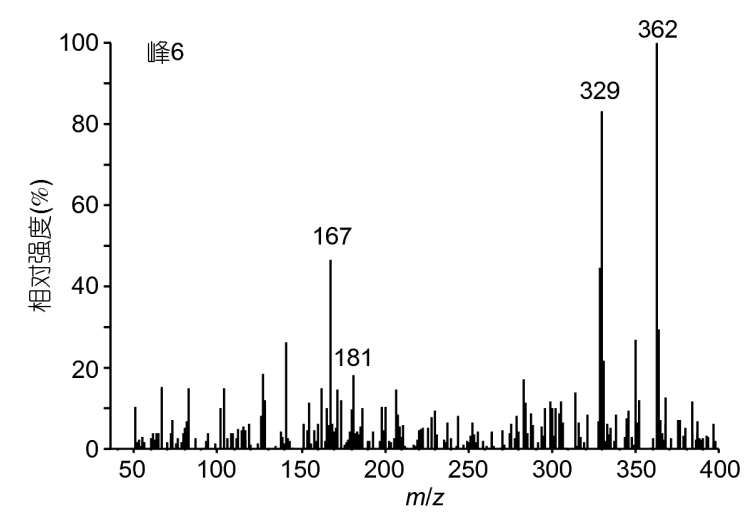

图 7 “假”五金刚烷硫醇质谱图

构体(峰C、D、H)及甲基四金刚烷分布(图8峰B). 图9 显示了图8中B、C、D峰的质谱图，B、C、D峰的质 谱特征与Lin和Wilk(1995)吻合度高. 无烷基取代的四 金刚烷由于分子结构稳定性高，质谱特征以分子离子 $\left[\mathrm{M}^{+}\right]=292$ 为基峰作为特征(图9b峰C). 甲基四金刚烷的 基峰为 291 , 分子离子为 306 , 基峰 $m / z$ 291是在电子轰 击下，甲基四金刚烷分子离子 $\left[\mathrm{M}^{+}\right]=306$ 丢失一个甲基 形成的(图9a峰B). 图9c中D号峰代表为四金刚烷、 $\mathrm{C}_{1}$ 烷基取代四金刚烷、 $\mathrm{C}_{2}$ 烷基取代四金刚烷的共溢出峰 的质谱图, 质谱图除了以 $m / z$ 292作为基峰外, 含有 $m /$ $z 306 、 320$ 碎片离子, 分别代表 $\mathrm{C}_{1}$ 取代和 $\mathrm{C}_{2}$ 取代四金刚 烷的分子离子.

\section{5 五金刚烷系列}

中深1C井原油饱和烃组分中可检测出五金刚烷 化合物系列, 离子信号只在2000左右, 无法获得满意的 质谱图. $m / z$ 344质量色谱图显示了浓缩后的中深1C井

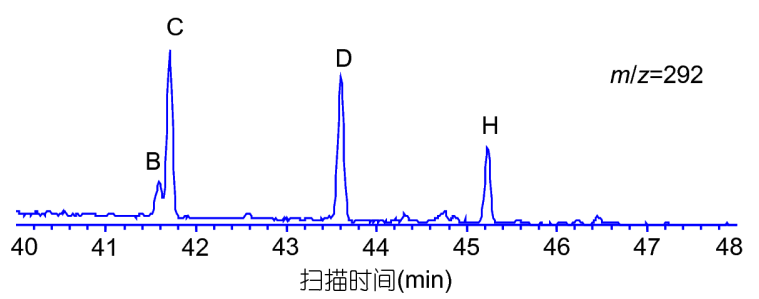

图 8 四金刚烷质量色谱图

原油饱和烃中可能为五金刚烷的 4 个异构体 (峰M 峰 P)及甲基五金刚烷(峰L)的分布(图10). 图11a显示了五 金刚烷 (峰号 $\mathrm{N}$ )的质谱图, 五金刚烷质谱以分子离子 $\mathrm{m} / \mathrm{z} 344$ 为基峰, 其他的碎片离子较少(图11a), 与Lin和 Wilk(1995)结果吻合度高; 甲基五金刚烷质谱图中以 $\mathrm{m} / \mathrm{z} 343$ 为基峰, 分子离子 $\left[\mathrm{M}^{+}\right]=358$ 强度在 $40 \%$ 左右(图 $11 b)$, 基峰 $m / z 343$ 是由于甲基五金刚烷分子离子易于 丢失甲基造成的.

\section{6 六金刚烷及环六金刚烷系列}

六金刚烷系列及环六金刚烷(附录1)仅在中深1C 井浓缩原油的饱和烃检出. $\mathrm{m} / \mathrm{z}$ 396质量色谱图显示了 浓缩后原油饱和烃中六金刚烷的分布(图12a). 由于六 金刚烷含量较低, 信噪比低, 未能获取清晰的质谱图. 六金刚烷的辨识是通过文献的保留时间和保留位置确 定的(Lin和Wilk, 1995). 质谱图中七个阴影标识的峰可 能为六金刚烷的7个不同的同分异构体. $m / z$ 342质量 色谱图显示了环六金刚烷的分布(图12b), 环六金刚烷 以强的分子离子峰为特征, 具有双电荷分子离子 $m / z$ 171, 其他的碎片离子很少(图13), 与Dahl等(2003b)结 果一致.
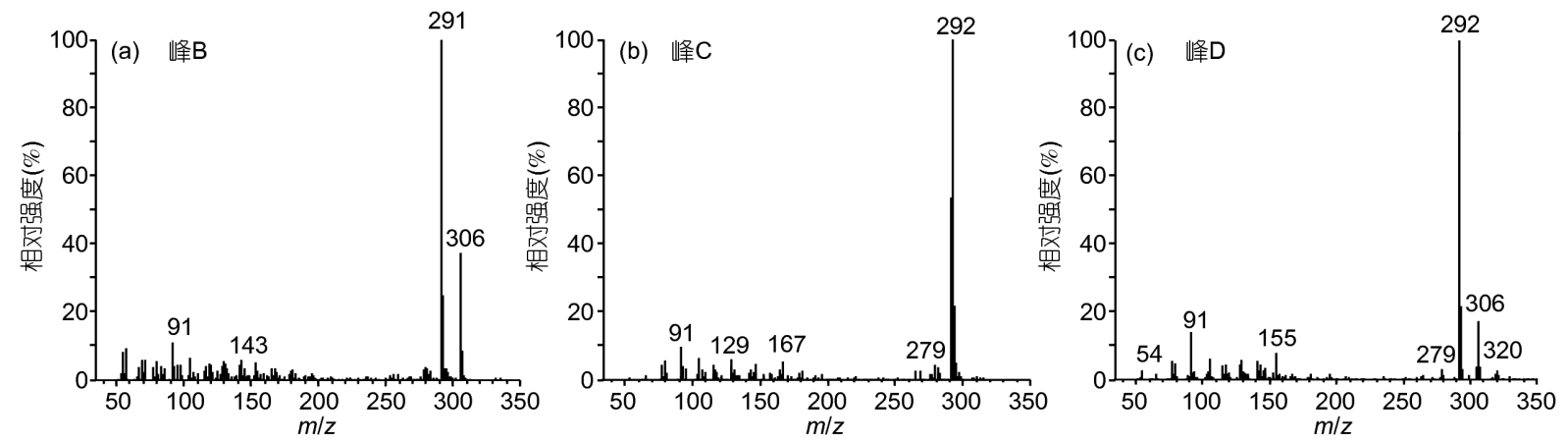

图 9 甲基四金刚烷(峰B)、四金刚烷(峰C)、四金刚烷与甲基四金刚烷及二甲基四金刚烷(峰D)质谱图 


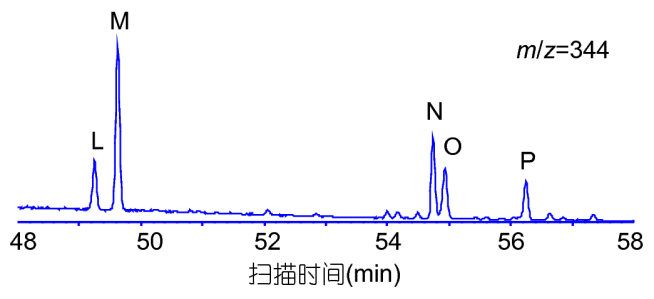

图 10 五金刚烷质量色谱图

\section{4 讨论}

\section{1 高聚金刚烷的成因}

目前除了确认活的生物体中不含有金刚烷化合物 外, 有关低聚金刚烷化合物的确切成因并不清楚. 普遍 认为是三环烃类在强Lewis酸的催化重排下形成的 (Petrov等, 1974), 在原油裂解过程和TSR过程中, 也可 以形成低聚金刚烷(Fang等，2012，2013; 王广利等, 2013; Cai等, 2016a).

高聚金刚烷在原油中含量很低，若将三金刚烷含 量作为 1 的话，四金刚烷含量为三金刚烷含量的 $0.1 \sim 0.01$, 五金刚烷含量为三金刚烷含量的 $0.01 \sim 0.001$, 而环六金刚烷含量为三金刚烷含量的 $0.001 \sim 0.0001$ (Moldowan等, 2013), 因而高聚金刚烷分析通常需要浓
缩原油样品或者特殊处理才能满足检测下限要求。高 聚金刚烷的内组成与烃源岩母质来源密切相关，其含 量及组成并可用作晚期生油及之后阶段油油对比的指 标(Moldowan等, 2013, 2015; Dahl等, 2017). 由于实验 室条件下合成高聚金刚烷十分困难, 且产率较低, 低聚 金刚烷可通过同系化反应合成聚合度高一级的金刚 烷，但目前实验室条件下合成聚合度最高的金刚烷是 四金刚烷(Burns等，1978). 基于上述理念，Lin和Wilk (1995)提出石油中的高聚金刚烷是低聚金刚烷经同系 化作用形成的. Dahl等 $(2010)$ 使用三金刚烷在 $500^{\circ} \mathrm{C}$, 加热 $4 \mathrm{~d}$ 后，或在Easy $R_{0}>3.7 \%$ 之后，合成了高聚金刚烷， 认为三金刚烷裂解的自由基反应可以形成高聚金刚 烷. 对于环六金刚烷, 由于其单体碳同位素介于 25 30\% 之间，与原油碳同位素接近，暗示了其有机成 因(Dahl等, 2003b).

未浓缩的塔里木盆地原油饱和烃中, 在色质全扫 描中能检测到高聚金刚烷的原油仅有中深1C井、顺 南1井(可检测到五金刚烷)和罗斯2井(可检测到四金刚 烷)奥陶系原油. 能检测出高聚金刚烷的原油通常低聚 金刚烷化合物含量很高, 如中深1C井原油中4-甲基+3甲基双金刚烷含量在 $3624 \mu \mathrm{g} / \mathrm{g}$ (表1)，顺南1井奥陶系 原油中4-甲基+3-甲基双金刚烷含量为 $707 \mu \mathrm{g} / \mathrm{g}$ (马安来
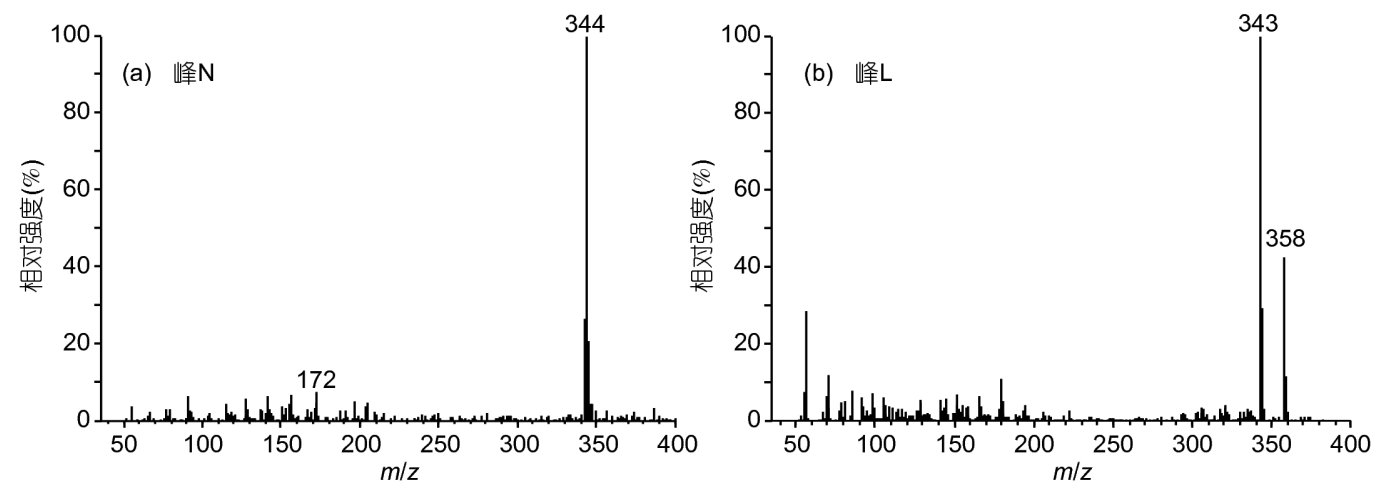

图 11 五金刚烷(a, 峰 $N$ )和甲基五金刚烷(b, 峰 $\mathrm{L}$ )质谱图
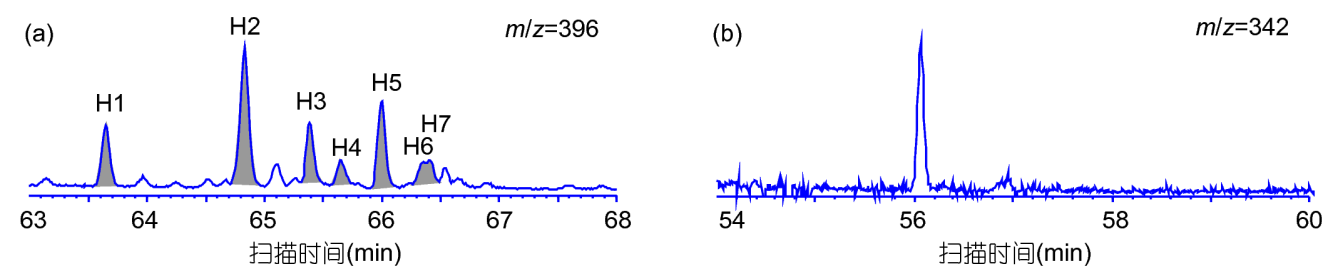

图 12 六金刚烷(a)和环六金刚烷(b)质量色谱图 


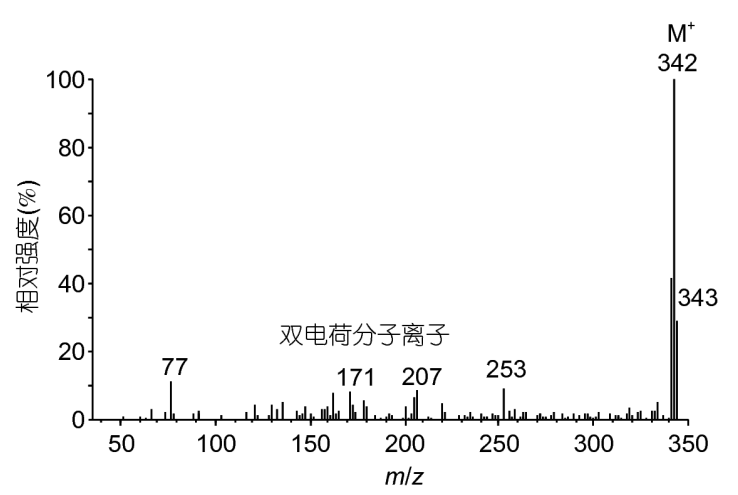

图 13 环六金刚烷化合物质谱图

等, 2018), 罗斯2井奥陶系原油中4-甲基+3-甲基双金刚 烷含量为 $150 \mu \mathrm{g} / \mathrm{g}$. 而中深1井中寒武统阿瓦塔格组原 油 4 - 甲基+3-甲基双金刚烷含量为 $25 \mu \mathrm{g} / \mathrm{g}, \mathrm{Ca}$ 等 (2016b)认为遭受TSR作用的塔中 83 井奥陶系鹰山组原 油，本次分析其4-甲基+3-甲基双金刚烷含量为 $93 \mu \mathrm{g} / \mathrm{g}$, 塔河油田奥陶系原油中4-甲基+3-甲基双金刚烷含量 为4 73 $\mu \mathrm{g} / \mathrm{g}$ (马安来等, 2009, 2017), 这些原油中无一能 检出四金刚烷．再如Lin和Wilk(1995)首次发表检出高 聚金刚烷的Mobile Bay原油, 气油比达到 $595238 \mathrm{~m}^{3} / \mathrm{m}^{3}$, 表明该原油经历了较强的热裂解作用和(或)TSR作用. 根据目前塔里木盆地海相原油的甲基双金刚烷含量, 其4-甲基+3-甲基双金刚烷含量至少要在 $100 \mu \mathrm{g} / \mathrm{g}$ 左右, 原油才有可能经历了较为明显的TSR作用.

中深1C井原油中高聚金刚烷可能是原油在TSR过 程作用中形成的，从中深1、中深1C井中寒武统、下 寒武统原油的甲基双金刚烷含量来看，中深1C井原油 的 4-甲基+3-甲基双金刚烷含量约为中深 1 井原油的
145倍，中深1、中深1C井原油在埋藏深度的差异在 $435 \sim 447 \mathrm{~m}$, 若按地温梯度 $2.2^{\circ} \mathrm{C} / 100 \mathrm{~m}$ 计算，两者之间 地温的差异在 $10^{\circ} \mathrm{C}$ 以下. Zhang等 $(2015 b)$ 认为中深 1 井 阿瓦塔格组温度为 $155^{\circ} \mathrm{C}$, 中深 $1 \mathrm{C}$ 肖尔布拉克组油藏 的温度仅在 $163^{\circ} \mathrm{C}$, 两口钻井之间 $8^{\circ} \mathrm{C}$ 的温度差异不支 持两者之间甲基金刚烷含量的巨大差异. 从目前中深 1、中深 $1 \mathrm{C}$ 井寒武系温度折算的Easy $R_{\mathrm{o}}$, 也不支持正 构烷烃自由基反应形成高聚金刚烷，因而中深1C井原 油高聚金刚烷可能是TSR作用下形成的，进一步支持 Cai等(2016a)高聚金刚烷为TSR作用的产物. 此外, 在 饱和烃全扫描分析能检测出四金刚烷的顺南1井、罗 斯2井原油均经历了不同程度的TSR作用(马安来等, 2018; 朱心健等, 2017), 表明TSR过程中确实生成了高 聚金刚烷. 因而在使用高聚金刚烷含量及内组成划分 不同油簇时需要考虑TSR作用对其含量及内组成的 影响.

\section{2 高聚硫代金刚烷及金刚烷硫醇的成因}

虽然三环硫化物在强酸的催化重排下可以形成硫 代单金刚烷，烃源岩在热演化过程中也可形成痕量的 硫代单金刚烷，然而显著含量的硫代单金刚烷是在原 油遭受硫酸盐热化学还原作用(TSR)下形成的(Hanin 等, 2002; Wei等, 2007b; Cai等, 2016a, 2016b).

对单金刚烷和烷基单金刚烷模型化合物TSR模拟 实验表明在TSR过程中可以形成单金刚烷硫醇，因而 元素硫和多硫化物可以直接攻击单金刚烷的季碳位置 形成1-单金刚烷硫醇, 或者攻击单金刚烷仲碳位置形 成2-单金刚烷硫醇(Wei等, 2007b). 与单金刚烷硫醇形 成机理类似，高聚金刚烷硫醇可以直接来源于高聚金

表 1 中深 $1 C$ 、中深1井及有关奥陶系原油中金刚烷化合物及 $\mathrm{C}_{29}$ 甾烷含量

\begin{tabular}{cccccccc}
\hline & & & \multicolumn{5}{c}{ 含量 $(\mu \mathrm{g} / \mathrm{g})$} \\
\cline { 5 - 8 } 井号 & 井深 $(\mathrm{m})$ & 层位 & 金刚烷 & 单金刚烷 & 双金刚烷 & $\begin{array}{c}\text { 4-甲基+3-甲基双金刚烷 } \\
\text { (未校正)/校正 }\end{array}$ & $\mathrm{C}_{29} \alpha \alpha \alpha 20 \mathrm{R}^{\mathrm{a})}$ \\
\hline 中深1C & $6861 \sim 6944$ & $\epsilon_{1} x$ & 83874.20 & 57585.83 & 26288.37 & $8008.31 / 3623.67$ & - \\
中深1 & $6426 \sim 6497$ & $\epsilon_{2} a$ & 2180.27 & 2004.16 & 176.11 & $54.61 / 24.71$ & 5.26 \\
塔中83 & $5666.10 \sim 5686.00$ & $\mathrm{O}_{1-2} y$ & 6759.10 & 6080.49 & 678.60 & $206.56 / 93.46$ & - \\
罗斯2 & $5741 \sim 5830$ & $\mathrm{O}_{1} p$ & 10818.17 & 9650.79 & 1167.39 & $331.32 / 149.92$ & - \\
顺南1 & $6528.24 \sim 6690.00$ & $\mathrm{O}_{2} y j+\mathrm{O}_{1-2} y$ & 37845.60 & 32759.77 & 5338.32 & $1562.10 / 706.83$ & 12.86 \\
顺北1-2 & $7469.00 \sim 7569.47$ & $\mathrm{O}_{2} y j$ & 1077.89 & 981.73 & 96.17 & $28.49 / 12.89$ & 8.91 \\
\hline
\end{tabular}

a) - 表示未检出 
刚烷与还原硫化物的反应(Wei等, 2011), 图14a展示了 四金刚烷形成四金刚烷硫醇的机理. 由于硫元素不能 直接进入到单金刚烷笼形结构中置换碳原子，在TSR 过程中单金刚烷笼形结构在硫自由基的攻击下，笼形 结构中C-C键发生断裂，笼形结构的断裂涉及了笼形 结构中仲碳位置的两个 $\mathrm{C}-\mathrm{C}$ 键的断裂，随后在仲碳位 置添加-SH官能团, 形成开笼的似单金刚烷硫醇, 似单 金刚烷硫醇可与还原硫化物反应，接着进行环化形成 硫代单金刚烷(Wei等, 2007b). 与硫代单金刚烷形成相 似, 图14b展示了四金刚烷形成硫代四金刚烷过程.

具有高聚硫代金刚烷和高聚金刚烷硫醇的原油通 常含有较高含量的低聚硫代金刚烷和金刚烷化合物, 如Wei等(2011)检测出高聚硫代金刚烷的Mobile Bay地 区的Bon Secour Bay 63-1、78-1油田原油, 原油低聚硫 代金刚烷含量在222 300 $\mu \mathrm{g} / \mathrm{g} ， 4$-甲基+3-甲基双金刚 烷含量为8301 8668 $\mu \mathrm{g} / \mathrm{g}$ ，中深1C井原油低聚硫代金
刚烷化合物含量为 $8578 \mu \mathrm{g} / \mathrm{g}$ (表2), 顺南1井奥陶系原 油仅能检测到硫代四金刚烷和四金刚烷硫醇，低聚硫 代金刚烷含量为 $80 \mu \mathrm{g} / \mathrm{g}$ (马安来等，2018). 虽然罗斯2 井原油具有较高的低聚硫代金刚烷含量, 但是在低聚 硫代金刚烷中以硫代单金刚烷为主，占低聚硫代金刚 烷组成的 $66 \%$ ，而硫代三金刚烷含量仅占组成的 $3 \%$, 该原油未检测出高聚硫代金刚烷.同为寒武系的中深1 井阿瓦塔格组原油低聚硫代金刚烷含量为 $7 \mu \mathrm{g} / \mathrm{g}$, 该原 油也未能检测到高聚硫代金刚烷.中深1C原油低聚硫 代金刚烷含量远远大于Cai等(2016a)提出TSR反应的 门槛值为 $28 \mu \mathrm{g} / \mathrm{g}$ ，表明中深 $1 \mathrm{C}$ 井原油遭受了强烈的 TSR作用，也从侧面支持高聚硫代金刚烷、高聚金刚 烷硫醇的TSR成因. 从遭受明显TSR作用的顺南 1 、罗 斯2、中深1C井原油中低聚硫代金刚烷含量来看，遭 受明显TSR作用的原油低聚硫代金刚烷含量应在 $80 \mu \mathrm{g} / \mathrm{g}$ 左右. 以后随着测试样品的积累, 该界限值会有

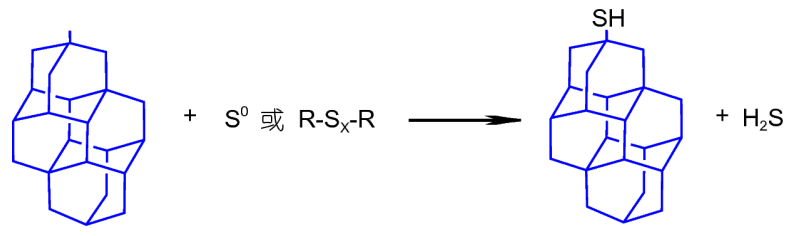

(a)

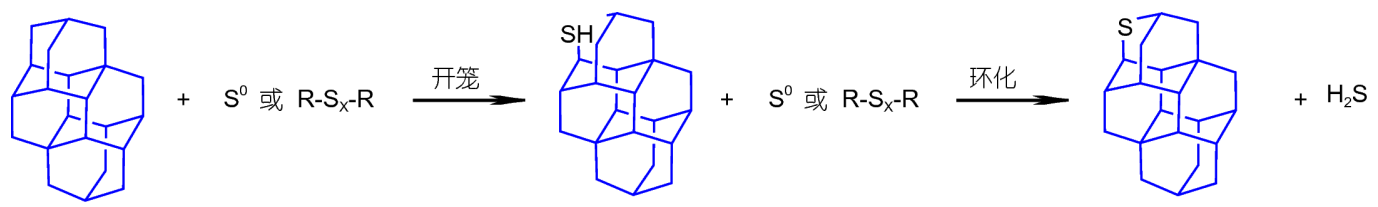

(b)

图 14 高聚硫代金刚烷及高聚金刚烷硫醇的形成机理, 以四金刚烷硫醇和硫代四金刚烷为例

(a) 四金刚烷硫醇形成机理; (b)硫代四金刚烷形成机理

表 2 中深1C、中深1井寒武系原油及有关奥陶系原油低聚硫代金刚烷含量

\begin{tabular}{|c|c|c|c|c|c|c|c|}
\hline \multirow{2}{*}{ 井号 } & \multirow{2}{*}{ 井深(m) } & \multirow{2}{*}{ 层位 } & \multicolumn{5}{|c|}{ 含量 $(\mu \mathrm{g} / \mathrm{g})$} \\
\hline & & & 低聚硫代金刚烷 & 低挥发硫代金刚烷 ${ }^{a)}$ & 硫代单金刚烷 & 硫代双金刚烷 & 硫代三金刚烷 \\
\hline 中深1C & $6861 \sim 6944$ & $\epsilon_{1} x$ & 8578.02 & 6750.71 & 3980.22 & 3770.93 & 826.88 \\
\hline 中深1 & $6426 \sim 6497$ & $\epsilon_{2} a$ & 7.36 & 5.11 & 6.32 & 0.79 & 0.26 \\
\hline 塔中83 & $5666.10 \sim 5686.00$ & $\mathrm{O}_{1-2} \mathrm{y}$ & 36.04 & 21.97 & 29.83 & 4.84 & 1.37 \\
\hline 罗斯2 & $5741 \sim 5830$ & $\mathrm{O}_{1} p$ & 192.01 & 127.29 & 159.62 & 26.45 & 5.93 \\
\hline 顺南1 & $6528.24 \sim 6690.00$ & $\mathrm{O}_{2} y j+\mathrm{O}_{1-2} y$ & 79.88 & 73.95 & 21.27 & 31.49 & 27.12 \\
\hline 顺北1-2 & $7469.00 \sim 7569.47$ & $\mathrm{O}_{2} y j$ & 5.84 & 4.27 & 4.39 & 0.89 & 0.56 \\
\hline
\end{tabular}

a) 低挥发硫代金刚烷: 即不含 $\mathrm{C}_{0}-\mathrm{C}_{2}$ 硫代单金刚烷化合物, 因 $\mathrm{C}_{0}-\mathrm{C}_{2}$ 硫代单金刚烷挥发性较强, 在样品处理过程中, 容易挥发损失 
所变化. 本研究中高聚金刚烷可以检测达六金刚烷, 而 高聚硫代金刚烷和金刚烷硫醇只可以检测到硫代五金 刚烷和五金刚烷硫醇，也从侧面说明高聚金刚烷可能 是高聚硫代金刚烷和高聚金刚烷硫醇的母体(Wei等, 2011).

\section{3 中深1C井原油高聚硫代金刚烷检出的意义}

中深1C井寒武系原油全油 $\delta^{34} \mathrm{~S}$ 同位素为 $33 \%$, 天 然气 $\mathrm{H}_{2} \mathrm{~S}$ 的 $\delta^{34} \mathrm{~S}$ 为 $33.5 \%$ ，与寒武系石膏 $\delta^{34} \mathrm{~S}$ 分布范围 为32 37\%o接近(Cai等, 2016b; Zhu等，2016); 原油二 苯并噻吩系列 $\delta^{34} \mathrm{~S}$ 分布范围为34.4 38.5\% , 平均值在 $36.2 \%$ o(Cai等，2016b)或者37\%o(Li等，2015)，原油硫代 单金刚烷和硫代双金刚烷 $\delta^{34} \mathrm{~S}$ 同位素分布范围为 $39.4 \sim 41.4 \%$, 平均值为 $39.7 \%$ (Cai等, 2016b), 全油、单 体硫化物、天然气 $\mathrm{H}_{2} \mathrm{~S}$ 的 $\delta^{34} \mathrm{~S}$ 同位素均为海相油气藏 最重的，一致表明中深1C井原油遭受了强烈的TSR作 用(Cai等，2016b); 而Zhang等(2015b)认为中深1C井原 油的TSR并非最严重的原油，埋深大于 $7000 \mathrm{~m}$ 的地层 可能发生更为强烈的 TSR作用, $\mathrm{H}_{2} \mathrm{~S}$ 和二苯并噻吩均可 从深部地层中运移上来. Zhu等(2015b)认为中深1C井 原油为TSR蚀变的残余油，但天然气主要为干酷根裂 解气，含有一部分原油二次裂解气的贡献，天然气中 可变的 $\mathrm{H}_{2} \mathrm{~S}$ 含量源于深部地层的TSR原位蚀变的初始 阶段并向上运移形成的.

在中深1C井原油中不仅检测到高聚金刚烷系列, 同时还可检测到高聚硫代金刚烷和高聚金刚烷硫醇系 列，由于高聚硫代金刚烷、高聚金刚烷硫醇系列含量 的形成与富集需要TSR达到较高程度才能进行, 因此 中深1C井原油高聚硫代金刚烷和高聚金刚烷硫醇的 检出, 为中深 $1 \mathrm{C}$ 井寒武系原油为严重TSR作用残余油 提供了有利证据. 严重TSR作用是导致中深1、中深 $1 \mathrm{C}$ 井原油地球化学特征明显差异的重要原因.

\section{5 结论}

(1) 中深1C井下寒武统肖尔布拉克组原油含硫非 烃中可以检测到高聚硫代金刚烷和高聚金刚烷硫醇系 列，包括硫代四金刚烷、四金刚烷硫醇、硫代五金刚 烷、五金刚烷硫醇系列，高聚硫代金刚烷与金刚烷硫 醇系列为塔里木盆地原油首次报道.

(2) 中深1C井下寒武统肖尔布拉克组原油饱和烃
中可以检测到四金刚烷、五金刚烷、六金刚烷、环六 金刚烷系列, 环六金刚烷为塔里木盆地原油首次报道.

(3) 中深1C井下寒武统肖尔布拉克组原油高聚硫 代金刚烷、高聚金刚烷硫醇、高聚金刚烷系列的检出 进一步支持中深 $1 \mathrm{C}$ 井原油为 TSR 强烈蚀变的残余原 油. 高聚硫代金刚烷和高聚金刚烷硫醇可作为强烈 TSR作用的分子标志物. 严重TSR作用是造成中深1、 中深1C井原油地球化学特征差异的重要因素.

（4）塔里木盆地地温梯度相对较低，在埋深近 $8000 \mathrm{~m}$ 的奥陶系储层中，地层温度仍然低于 $160^{\circ} \mathrm{C}$, 原 油热裂解作用较低, 目前已发现的油气藏遭受TSR作 用强度相对较低. 因此在顺北、热瓦普地区奥陶系深 部油气藏以挥发性油气藏和轻质油藏为主. 随着勘探 向寒武系的进军, 需要密切关注TSR作用对油气藏的 次生改造作用.

致谢评审专家富有建设性的修改意见对本文的完善和 提升具有重要作用, 对此深表感谢.

\section{参考文献}

马安来, 金之钧, 朱翠山, 彭守涛, 张卫彪. 2009. 塔河油田原油中金 刚烷化合物绝对定量分析. 石油学报, 30: 214-218

马安来. 2016. 金刚烷类化合物在有机地球化学中的应用进展. 天然 气地球科学, 27: 851-860

马安来, 金之钧, 朱翠山. 2017. 塔里木盆地塔河油田奥陶系原油成 熟度及裂解程度研究. 天然气地球科学, 28: 313-323

马安来, 金之钧, 朱翠山. 2018. 塔里木盆地顺南1井原油硫代金刚烷 系列的检出及意义. 石油学报, 39: 42-53

宋到福, 王铁冠, 李美俊. 2016. 塔中地区中深1和中深1C井盐下寒武 系油气地球化学特征及其油气源判识. 中国科学: 地球科学, 46: $107-117$

姜乃煌, 朱光有, 张水昌, 王政军. 2007. 塔里木盆地塔中83井原油中 检测出2-硫代金刚烷及其地质意义. 科学通报, 52: 2871-2875

王道伟, 王铁冠, 李美俊, 宋到福, 师生宝. 2016. 塔中隆起中深5井与 中深1井䓛和烷基䓛分布特征与油源启示. 地球化学，45：451461

王广利, 李宁熙, 高波, 李贤庆, 师生宝, 王铁冠. 2013. 麻江奥陶系古 油藏中的硫酸盐热化学还原反应: 来自分子标志物的证据. 科学 通报, 58: 3450-3457

王招明, 谢会文, 陈永权, 齐英敏, 张科. 2014. 塔里木盆地中深1井寒 武系盐下白云岩原生油气藏的发现与勘探意义. 中国石油勘探, 19: $1-12$

张纪智, 王照明, 杨海军, 徐志明, 肖中尧, 李中珓. 2017. 塔里木盆地 
中深地区寒武系盐下白云岩油气来源及差异聚集. 石油勘探与 开发, 44: 40-47

朱心健, 陈践发, 贺礼文, 王艺繁, 张威, 张宝收, 张科. 2017. 塔里木 盆地麦盖提斜坡罗斯 2 井油气地球化学特征及油气源分析. 天然 气地球科学, $28: 566-574$

Ali Mansoort G, de Araujo P L B, de Araujo E S. 2012. Diamondoid Molecules with Applications in Biomedicine, Materials Sciences, Nanotechnology \& Petroleum Science. Singapore: World Scientific Publishing Co. Pte. Ltd

Burns W, McKervey M A, Mitchell T R B, Rooney J J. 1978. A new approach to the construction of diamondoid hydrocarbons. Synthesis of anti-tetramantane. J Am Chem Soc, 100: 906-911

Cai C, Zhang C, Worden R H, Wang T, Li H, Jiang L, Huang S, Zhang

B. 2015. Application of sulfur and carbon isotopes to oil-source rock correlation: A case study from the Tazhong area, Tarim Basin, China. Org Geochem, 83-84: 140-152

Cai C, Xiao Q, Fang C, Wang T, He W, Li H. 2016a. The effect of thermochemical sulfate reduction on formation and isomerization of thiadiamondoids and diamondoids in the Lower Paleozoic petroleum pools of the Tarim Basin, NW China. Org Geochem, 101: 4962

Cai C, Amrani A, Worden R H, Xiao Q, Wang T, Gvirtzman Z, Li H, Said-Ahmad W, Jia L. 2016b. Sulfur isotopic compositions of individual organosulfur compounds and their genetic links in the Lower Paleozoic petroleum pools of the Tarim Basin, NW China. Geochim Cosmochim Acta, 182: 88-108

Chen J, Fu J, Sheng G, Liu D, Zhang J. 1996. Diamondoid hydrocarbon ratios: novel maturity indices for highly mature crude oils. Org Geochem, 25: 179-190

Dahl J E, Moldowan J M, Peters K E, Claypool G E, Rooney M A, Michael G E, Mello M R, Kohnen M L. 1999. Diamondoid hydrocarbons as indicators of natural oil cracking. Nature, 399: 54 57

Dahl J E, Liu S G, Carlson R M K. 2003a. Isolation and structure of higher diamondoids, nanometer-sized diamond molecules. Science, 299: 96-99

Dahl J E P, Moldowan J M, Peakman T M, Clardy J C, Lobkovsky E, Olmstead M M, May P W, Davis T J, Steeds J W, Peters K E, Pepper A, Ekuan A, Carlson R M K. 2003b. Isolation and structural proof of the large diamond molecule, cyclohexamantane $\left(\mathrm{C}_{26} \mathrm{H}_{30}\right)$. Angew Chem Int Ed, 42: 2040-2044

Dahl J E P, Moldowan J M, Wei Z, Lipton P A, Denisevich P, Gat R, Liu S, Schreiner P R, Carlson R M K. 2010. Synthesis of higher diamondoids and implications for their formation in petroleum. Angew Chem Int Ed, 49: 9881-9885

Dahl J E, Moldowan J M, Koskella D L. 2017. Source identification of
Permian basin oils using higher diamondoids. In: Proceedings of the 28th International Meeting on Organic Geochemistry IMOG 2017, Florence, Italy, 17-22 September. 1-268

Grice K, Alexander R, Kagi R I. 2000. Diamondoid hydrocarbon ratios as indicators of biodegradation in Australian crude oils. Org Geochem, 31: 67-73

Hanin S, Adam P, Kowalewski I, Huc A Y, Carpentier B, Albrecht P. 2002. Bridgehead alkylated 2-thiaadamantanes: Novel markers for sulfurisation processes occurring under high thermal stress in deep petroleum reservoirs. Chem Commun, 16: 1750-1751

Fang C, Xiong Y, Liang Q, Li Y. 2012. Variation in abundance and distribution of diamondoids during oil cracking. Org Geochem, 47: $1-8$

Fang C, Xiong Y, Li Y, Chen Y, Liu J, Zhang H, Adedosu T A, Peng P. 2013. The origin and evolution of adamantanes and diamantanes in petroleum. Geochim Cosmochim Acta, 120: 109-120

Gvirtzman Z, Said-Ahmad W, Ellis G S, Hill R J, Moldowan J M, Wei Z, Amrani A. 2015. Compound-specific sulfur isotope analysis of thiadiamondoids of oils from the Smackover Formation, USA. Geochim Cosmochim Acta, 167: 144-161

Li S, Amrani A, Pang X, Yang H, Said-Ahmad W, Zhang B, Pang Q. 2015. Origin and quantitative source assessment of deep oils in the Tazhong Uplift, Tarim Basin. Org Geochem, 78: 1-22

Lin R, Wilk Z A. 1995. Natural occurrence of tetramantane $\left(\mathrm{C}_{22} \mathrm{H}_{28}\right)$, pentamantane $\left(\mathrm{C}_{26} \mathrm{H}_{32}\right)$ and hexamantane $\left(\mathrm{C}_{30} \mathrm{H}_{36}\right)$ in a deep petroleum reservoir. Fuel, 74: 1512-1521

Moldowan J M, Zinniker D, Moldowan S, Dahl J. 2013. Novel technologies for unraveling the charge history of multiply-sourced petroleum systems. In: AAPG Hedberg Research Conference, "Fundamental Controls on Petroleum Systems in Lower Paleozoic and Older Strata", Beijing, China, April 21-24, 2013. http://www. searchanddiscovery.com/abstracts/html/2013/90175hedberg/abstracts/mol.htm

Moldowan J M M, Dahl J, Zinniker D, Barbanti S M. 2015. Underutilized advanced geochemical technologies for oil and gas exploration and production-1. The diamondoids. J Pet Sci Eng, 126: $87-96$

Petrov A, Arefjev O A, Yakubson Z V. 1974. Hydrocarbons of adamantane series as indices of petroleum catagenesis process. In: Tissot B, Bienner F, eds. Advances in Organic Geochemistry 1973. Paris: Editions Technip. 517-522

Sassen R, Post P. 2008. Enrichment of diamondoids and ${ }^{13} \mathrm{C}$ in condensate from Hudson Canyon, US Atlantic. Org Geochem, 39: $147-151$

Wei Z, Moldowan J M, Jarvie D M, Hill R. 2006a. The fate of diamondoids in coals and sedimentary rocks. Geology, 34: 1013- 
1016

Wei Z. 2006b. Molecular organic geochemistry of cage compounds and biomarkers in the geosphere: A novel approach to understand petroleum evolution and alteration. Doctoral Dissertation. California: Stanford University. 275-375

Wei Z, Moldowan J M, Peters K E, Wang Y, Xiang W. 2007a. The abundance and distribution of diamondoids in biodegraded oils from the San Joaquin Valley: Implications for biodegradation of diamondoids in petroleum reservoirs. Org Geochem, 38: 854-863

Wei Z, Moldowan J M, Fago F, Dahl J E, Cai C, Peters K E. 2007b. Origins of thiadiamondoids and diamondoidthiols in petroleum. Energ Fuels, 21: 3431-3436

Wei Z, Mankiewicz P, Walters C, Qian K, Phan N T, Madincea M E, Nguyen P T H. 2011. Natural occurrence of higher thiadiamondoids and diamondoidthiols in a deep petroleum reservoir in the Mobile Bay gas field. Org Geochem, 42: 121-133

Wei Z, Walters C C, Michael Moldowan J, Mankiewicz P J, Pottorf R J, Xiao Y, Maze W, Nguyen P T H, Madincea M E, Phan N T, Peters K E. 2012. Thiadiamondoids as proxies for the extent of thermochemical sulfate reduction. Org Geochem, 44: 53-70

Wingert W S. 1992. G.c-m.s. analysis of diamondoid hydrocarbons in
Smackover petroleums. Fuel, 71: 37-43

Zhang S, Su J, Huang H, He K, Wang Y, Wang H, Zhang B, Wang X, Hu J. 2015a. Genetic origin of sour gas condensates in the Paleozoic dolomite reservoirs of the Tazhong Uplift, Tarim Basin. Mar Pet Geol, 68: 107-119

Zhang S, Huang H, Su J, Liu M, Wang X, Hu J. 2015b. Geochemistry of Paleozoic marine petroleum from the Tarim Basin, NW China: Part 5. Effect of maturation, TSR and mixing on the occurrence and distribution of alkyldibenzothiophenes. Org Geochem, 86: 5-18

Zhu G, Weng N, Wang H, Yang H, Zhang S, Su J, Liao F, Zhang B, Ji Y. 2015a. Origin of diamondoid and sulphur compounds in the Tazhong Ordovician condensate, Tarim Basin, China: Implications for hydrocarbon exploration in deep-buried strata. Mar Pet Geol, 62: $14-27$

Zhu G, Huang H, Wang H. 2015b. Geochemical significance of discovery in Cambrian Reservoirs at Well ZS1 of the Tarim Basin, Northwest China. Energ Fuels, 29: 1332-1344

Zhu G, Wang H, Weng N. 2016. TSR-altered oil with high-abundance thiaadamantanes of a deep-buried Cambrian gas condensate reservoir in Tarim Basin. Mar Pet Geol, 69: 1-12

(责任编委: 刘全有) 